\title{
Salud laboral y salud mental en población trabajadora inmigrante
}

\section{Occupational health and mental health in migrant worker population}

\author{
Macarena Gálvez Herrer ', María Dolores Gutiérrez García ', Nuria Zapico Martínez ${ }^{2}$ \\ 1. Programa de Atención Integral al Profesional Sanitario Enfermo (UVOPSE-PAIPSE). Comunidad Autónoma de Madrid. \\ España. \\ 2. Experta en Derecho Penal y Extranjería. Madrid. España.
}

\section{Correspondencia:}

Macarena Gálvez Herrer

UVOPSE-PAIPSE.

Pabellón 8, Ciudad Universitaria

28040 Madrid. España.

Tfno.: +34913303926

E-mail: mgalvez.hcsc@salud.madrid.org

Resumen

La motivación laboral es la principal razón del fenómeno migratorio. Supone romper barreras culturales, idiomáticas, tradiciones y vínculos afectivos, planteando a su vez retos personales, familiares, sociales y culturales, tanto en la sociedad de origen como en la receptora. Los procesos migratorios no suponen por si mismos problemas de salud mental, pero si plantean situaciones de alta vulnerabilidad y retos de integración.

Partiendo de una conceptualización de la salud mental como un bienestar físico, psicológico y social, en el presente artículo revisaremos la situación de esa fuerza trabajadora atendiendo a la complejidad de su situación legal, social y laboral y cómo todo ello se relaciona con su salud mental y salud laboral.

Palabras Clave: Trabajador inmigrante; salud mental; salud laboral.

Abstract

Working motivation is the main reason of the migratory phenomenon. It means breaking with cultural, social and language barriers, both in the society of origin as in the receiving. Migration processes do not themselves involve mental health problems, but they raise situations of high vulnerability and challenges of integration.

Based on a conceptualization of mental health as the physical, psychological and social well-being, in the present article we will review the legal status, social and labour, and how this relates to their mental and occupational health.

Key Words: Migrant worker; mental health; occupational bealth. 


\section{INTRODUCCIÓN}

Según la Declaración Universal de Derechos Humanos "Toda persona tiene derecho a circular libremente y elegir su residencia en el territorio de un Estado (Art. 13)", posee además "... derecho al trabajo, a la libre elección de su trabajo, a condiciones equitativas y satisfactorias de trabajo y a la protección contra el desempleo" (Art. 23). Los procesos migratorios son una cuestión de derecho, de economía de mercados, de globalización... pero sobretodo, son una cuestión que implica a personas.

Salir del país de origen para establecerse en otro lugar puede responder a múltiples motivaciones: académicas, económicas, políticas, religiosas o medioambientales (catástrofes naturales por ejemplo), pero la motivación laboral es la principal razón del fenómeno migratorio. Supone romper barreras culturales e idiomáticas, tradiciones y vínculos afectivos; planteando a su vez retos personales, familiares, sociales y culturales, tanto en la sociedad de origen como en la receptora. Los procesos migratorios no suponen por si mismos problemas de salud mental, pero si plantean situaciones de alta vulnerabilidad y retos de integración.

En el ámbito laboral, España ha sido un país principalmente emigrante. Hasta la década de los 60, América fue el principal receptor de trabajadores españoles, a partir de esas fechas, el desarrollo industrial de países europeos como Alemania, Francia o Suiza, les convirtió en el destino principal de parte de nuestra fuerza trabajadora, que comenzó a regresar progresivamente en flujos de retornados a partir de 1975 . Finalmente, en la última década del siglo $\mathrm{xx}$, se produce un importante cambio migratorio, convirtiéndose en un país de acogida. Recientemente, durante el año 2010, se ha producido el primer descenso de población extranjera en España. La crisis económica global afecta a todos los grupos laborales, y de forma especialmente significativa a los inmigrantes no comunitarios, que han reducido en gran medida su búsqueda de empleo en nuestro país, donde de los casi cinco millones de parados, más de un millón son de origen extranjero, siendo la construcción el sector más afectado en este sentido.

Según datos del presente año, del Instituto Nacional de Estadística ${ }^{2}$, la proporción de ciudadanos extranjeros sobre el total de la población residente en España se sitúa en el 12,2\%. Las comunidades con mayor proporción de extranjeros son Illes Balears (21,8\%), Comunitat Valenciana $(17,2 \%)$ y Comunidad de Madrid y Región de Murcia (ambas con 16,4\%). Por el contrario, las que tienen menor proporción de extranjeros son Extremadura (3,7\%), Galicia (3,9\%) y Principado de Asturias (4,7\%).

Respecto a la nacionalidad, los extranjeros residentes en España pertenecientes a la Unión Europea suman 2.392.491. Dentro de éstos, los más numerosos son los rumanos (864.278), seguidos por los del Reino Unido (390.880) y los alemanes (195.842). Entre los extranjeros no comunitarios, destacan los ciudadanos marroquíes (769.920), los ecuatorianos (359.076) y los colombianos (271.773).

Existe una progresiva feminización de los flujos migratorios, concretamente en España este aspecto es especialmente claro en entre el colectivo de nacionalidades iberoamericanas. Por el contrario, hay más varones en la mayoría de las nacionalidades africanas y asiáticas.

En relación con el sector de ocupación, en términos generales, se observan variaciones en función de la nacionalidad:

- Inmigrantes de la Unión Europea: ocupan frecuentemente el sector servicios (financiero, comercial o en el desempeño de profesiones liberales), ocupación en 
gran medida determinada por el nivel formativo medio y las facilidades de acreditación profesional.

- Población del Este de Europa: es la que, en proporción, más se emplea en la construcción (el doble que los españoles y casi tres veces más que los procedentes de la Unión Europea).

- Procedentes de América Latina: integrados prioritariamente en el sector de la hostelería y servicio doméstico.

- Marroquíes: conforman una parte importante del sector primario.

Todos estos grupos poblacionales están sometidos a la legislación española, forman parte de nuestro mercado de trabajo y comparten con la población trabajadora de nuestro país, los mismos problemas relativos a la salud laboral. Sin embargo, el proceso de integración en una nueva sociedad puede suponer además, factores de influencia específicos en su salud. El deterioro psicológico es un fenómeno en el que operan múltiples determinantes, algunos de ellos de carácter individual, pero otros de carácter social, como la integración comunitaria y laboral y las experiencias sociales en la sociedad receptora ${ }^{3}$.

En la relación del proceso migratorio podemos diferenciar diferentes fases y en cada una de ellas son diversos los posibles estresores personales y socio-laborales a los que se enfrenta el inmigrante:

1. Decisión de emigrar. Los mecanismos de adaptación se inician incluso antes de iniciar el viaje migratorio. En el momento de la toma de decisión de emigrar ya se ponen en marcha situaciones de estrés y ansiedad que pueden ser elaboradas por la persona con mayor o menor éxito y dificultad. Se producen los primeros contactos con familiares y redes informales de apoyo en el lugar de destino y se toman decisiones clave sobre aspectos como la estructura de la nueva configuración familiar (dejando hijos al cuidado de abuelos por ejemplo). Las propias vivencias y la repercusión de éstas sobre su salud, pueden incidir en el grado de bienestar posterior una vez se encuentre en la sociedad de acogida. Allí se enfrentará a situaciones de ganancia y pérdida de forma simultánea: para integrarse en "lo ajeno" necesitará reconocer "lo propio" (y por tanto lo que pierde de ello).

2. Llegada y adaptación. Tras un periodo que algunos autores denominan de "luna de miel", se confronta con una realidad que, en ocasiones, puede desencadenar sintomatología depresiva reactiva. A veces, en los primeros momentos, la incorporación laboral sólo es posible dentro de la economía sumergida, con acceso a trabajos precarios, sin contrato laboral, etc. La ansiedad se relaciona con el choque cultural, los procedimientos administrativos de regularización y permiso de trabajo, con el desconocimiento, la vulnerabilidad a engaños y la constante incertidumbre. La ausencia del grupo familiar de referencia se compensa con una estrecha vinculación a redes de apoyo de familiares, amigos y compatriotas.

3. Regularización. Si se produce incorporación al mercado de trabajo, predomina el acceso a puestos no deseados por la población autóctona y en ocasiones, la ausencia de correspondencia entre la formación-cualificación profesional y la ocupación obtenida. La necesidad de mantenerse de alta en la Seguridad Social no solo se debe a las prestaciones económicas y sociales que eso supone, está ligada también a poder renovar los permisos obtenidos. Es el momento personal en el que se suelen iniciar los procesos de reagrupación familiar.

4. Estabilización. Se obtiene una mejora social, mayor estabilidad laboral y en muchas ocasiones, la oportunidad de trabajar por cuenta propia, pero se mantienen problemas de homologación de títulos, necesidad de formarse para mejorar o adaptar la cualificación, y la discriminación en el acceso a puestos más cualificados. 
Superar este proceso supone afrontar una elevada ambivalencia emocional y numerosas pérdidas emocionales. A la motivación generada por la necesidad económica, las expectativas iniciales y el deseo de prosperar, se unen una elevada incertidumbre, la presión por no volver al país de origen sin conseguir el éxito, las dificultades de adaptación en la nueva sociedad, las dificultades en la regulación legal de su situación y los largos periodos de separación del grupo de referencia. El coste psicológico que suponen las dificultades laborales y personales puede ser muy alto.

Partiendo de una conceptualización de la salud mental como un bienestar físico, psicológico y social, en el presente artículo revisaremos la situación de esa fuerza trabajadora atendiendo a la complejidad de su situación legal, social y profesional y cómo todo ello se relaciona con su salud mental y salud laboral.

\section{INMIGRACIÓN Y TRABAJO: MARCO LEGAL}

Cuando el inmigrante llega a la sociedad de destino, una de sus principales metas consiste en regularizar su situación (obteniendo una autorización de residencia, o una autorización conjunta de trabajo y residencia) para lo cual deberá llevar a cabo una serie de trámites que marca la legislación vigente y que suponen la interacción con un entorno burocrático a menudo desconocido e incierto.

En España, tras la última reforma de la Ley Orgánica 2/2009 de 11 de diciembre, sobre derechos y libertades de los extranjeros en España ${ }^{4}$, se ha aprobado, con fecha 20 de Abril de 2011, el Reglamento que desarrolla dicha Ley Orgánica, mediante Real Decreto $557 / 2011^{5}$, conteniendo toda la normativa referida a la obtención de autorización de trabajo en nuestro territorio, con la pretensión de optimizar los principios de la política migratoria reconocidos a través de la Ley Orgánica mencionada, entre los que se encuentran la ordenación de los flujos migratorios laborales de acuerdo con la situación nacional de empleo, la integración social de las personas inmigrantes, la lucha contra la inmigración irregular y las relaciones con terceros países en materia de inmigración.

El Artículo 36 de la mencionada Ley, determina "Los extranjeros mayores de 16 años, precisarán para ejercer cualquier actividad lucrativa, laboral o profesional, de la correspondiente autorización administrativa previa para residir y trabajar. La autorización de trabajo se concederá conjuntamente con la de residencia. La autorización para trabajar o lo que comúnmente se conoce como el "Permiso de Trabajo", es el documento por el cual, una persona inmigrante no nacional, puede incorporarse al mercado laboral, bien sea para ejercer una actividad por cuenta propia, (artículo 37 de la L.O. 2/2009) bien sea para desarrollarla por cuenta ajena, (artículo 38 de la L.O. 2/2009). La obtención de dicha autorización, tras cumplir los requisitos que la Ley y el Reglamento mencionados exigen, habilita al extranjero para poder trabajar, durante un periodo concreto que se determinará reglamentariamente, tras el cual, deberá regresar a su país o solicitar la renovación del permiso concedido.

En este punto, es importante diferenciar al inmigrante que no posee titulación de estudios medios o superiores, del que si la posee, dado que si el objetivo de éste último es desarrollar una actividad laboral relacionada con los estudios cursados, deberá inscribirse en un colegio profesional, para lo cual tendrá que homologar su título ante el Ministerio de Educación, no siendo necesario para ello tener previamente permiso de residencia, sino tan sólo acreditar su identidad por medio del Pasaporte.

Si va a desarrollar un trabajo en otras áreas, deberá solicitar una "Credencial de Homologación a Grado", también en el Ministerio de Educación, que le sirve para dar validación al ciclo formativo universitario que haya terminado. Tanto en un caso como en otro, le posibilita el acceso al mercado de trabajo cualificado, debiendo solicitar el permiso de residencia y trabajo de acuerdo a la contratación que le sea ofertada, ante el Ministerio de Trabajo. 
Para los inmigrantes que carecen de titulación, el camino es más corto, iniciando directamente los trámites de solicitud de permiso de residencia y trabajo, de acuerdo a la actividad a desarrollar por cuenta propia, o a la contratación por cuenta ajena que les ha sido ofertada. En muchos casos, profesionales extranjeros altamente cualificados optan por esta opción para acortar esos plazos, evitar el paro y acceder al mercado laboral lo antes posible incorporándose a trabajos de baja cualificación. En un primer momento la prioridad de establecerse en nuestro país puede compensar la posible frustración personal y profesional, pero con el tiempo, la sobrecualificación para el puesto de trabajo desempeñado puede generar una importante pérdida de expectativas, sentimientos de baja autoeficacia profesional y desvalorización personal.

Las figuras legales para la incorporación del trabajador inmigrante serán:

1. Autorización de residencia y trabajo por cuenta propia. El solicitante extranjero, deberá cumplir todos los requisitos que la legislación vigente exige a los nacionales, para la apertura y funcionamiento de la actividad que pretende desarrollar, así como acreditar la suficiencia de la inversión, y la potencial creación de empleo. La autorización inicial se limitará a un sector concreto de actividad, y al ámbito geográfico de una Comunidad Autónoma. Así mismo, la duración se determinará reglamentariamente.

2. Autorización de residencia y trabajo por cuenta ajena. Para éste tipo de autorización se tendrá en cuenta la situación nacional de empleo, que será determinada por el Servicio Público de Empleo Estatal, en coordinación con las Comunidades Autónomas. La concesión de la autorización se basará en la solicitud de cobertura de un puesto vacante, presentada por un empresario o empleador, junto con el contrato de trabajo y el resto de documentación exigible.

$\mathrm{Al}$ igual que la anterior, la autorización inicial se limitará a un determinado territorio y ocupación. Así mismo, la duración se determinará reglamentariamente, si bien, a partir de la primera concesión, en sucesivas renovaciones, las autorizaciones se concederán sin limitación alguna de ámbito geográfico u ocupación.

Durante la vigencia de estos dos tipos, es posible modificar su alcance en cuanto a ocupación, sector de actividad y/o ámbito territorial, al amparo del artículo 203 del Reglamento que desarrolla la Ley, aprobado por Real Decreto 557/2011.

3. Régimen especial para los investigadores extranjeros. Regulado en el artículo 38 bis, contemplado para extranjeros cuya permanencia en España, tenga como único fin realizar proyectos de investigación, otorgando en esos supuestos una autorización de residencia y trabajo que se renovará anualmente, y que le habilitará a impartir clases o realizar otras actividades compatibles con la labor de investigación.

4. Autorización de residencia y trabajo para trabajadores altamente cualificados. Regulada en el artículo 38 ter, mediante la cual se expide al extranjero que goce de dicha cualificación, una autorización documentada con una tarjeta azul de la UE.

Resaltar por último dos tipos de tramitaciones especiales sometidas a aprobaciones puntuales: la tramitación especial denominada, "Gestión colectiva de contrataciones en origen”, que será aprobada por el Ministerio de Trabajo e Inmigración, según las cifras previstas, de empleos que se puedan cubrir a través de la gestión colectiva de contrataciones en origen, por un periodo determinado, destinada a aquellos extranjeros que no residen o no se hallen en España, y el "Régimen especial de trabajadores de temporada", regulado por el Gobierno para los trabajadores extranjeros en actividades de temporada o campaña, que les permita la entrada y salida del territorio español, fundamentalmente pensado para el sector agrario.

Según el Observatorio Permanente de la Inmigración en su Informe sobre Inmigración y Mercado de Trabajo ${ }^{6}$, parece que los efectos de la crisis económica no se relacionan con un aumento de la proporción de personas en situación irregular entre el colectivo de inmigrantes (ver gráfica 1). Según apuntan algunos análisis sobre los efectos de la crisis en los flujos migratorios, la inmigración irregular tiende a reducirse por ser muy sensible 
a las fluctuaciones de las ofertas de empleo. A su vez, se produce una reducción del empleo poco cualificado que repercute en un sector todavía importante de la población inmigrante.

Sí se llama la atención, en cambio, sobre un nuevo fenómeno en la procedencia de la irregularidad. Se trata de la situación de irregularidad sobrevenida en la que quedan aquellas personas que no han podido renovar su tarjeta de residencia al no cumplir los requisitos mínimos de cotización a la Seguridad Social exigidos. El propio informe da voz a una reclamación frecuentemente realizada por organizaciones que trabajan con inmigrantes: la posibilidad de que el tiempo de formación para el empleo también se tenga en cuenta para la renovación de las autorizaciones.

Gráfica 1. Afiliados extranjeros a la Seguridad Social según nacionalidad a 31 de diciembre de 2009

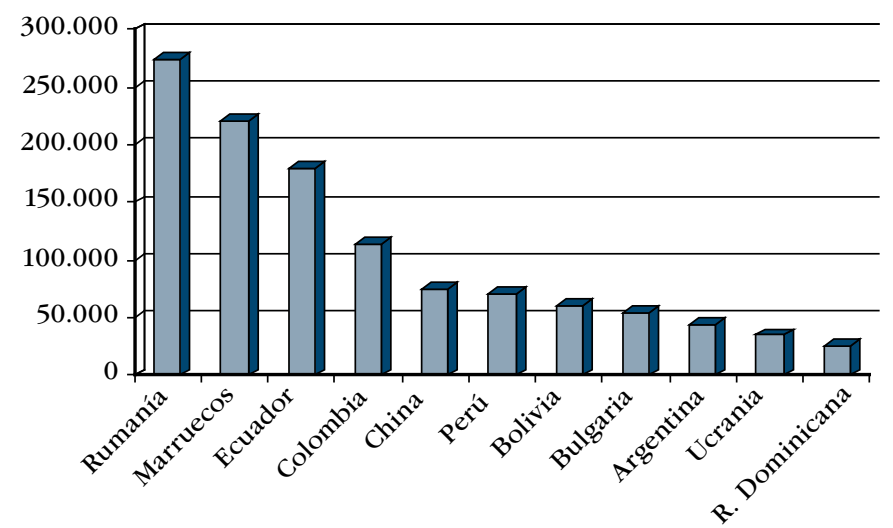

Fuente: Observatorio Permanente de la Inmigración. Secretaría de Estado de Inmigración y Emigración (2010).

Según Castillo y Prieto ${ }^{7}$, las circunstancias en las que se adquiere y mantiene el empleo conforman el inicio de lo que habitualmente denominamos "condiciones de trabajo". En el caso de los trabajadores extranjeros, ya hemos comentado las dificultades de acceso al mercado laboral, además de esas circunstancias, el nivel de estabilidad y seguridad en el mismo determinarán el proceso de socialización en el lugar de trabajo, el aprendizaje de valores relativos a la seguridad y prudencia en su desempeño laboral, la posibilidad de incrementar el tiempo de permanencia en la sociedad de acogida y una retribución estable que le permita ordenar y planificar, de cara a un futuro, su vida y la de su familia.

\section{CONDICIONES SOCIO-LABORALES Y SALUD LABORAL}

Como ya hemos apuntado en líneas anteriores, existe una clara segmentación del mercado de trabajo con nichos laborales reservados para los inmigrantes, y barreras de entrada a los trabajos más cualificados.

Respecto a la situación contractual también las diferencias son claras. En el año 2007, el último año de bonanza, más de la mitad de los trabajadores inmigrantes tenían contrato temporal $(52,6 \%)$, una tasa que duplicaba la de los españoles (27\%). Según los datos de la Encuesta de Estructura Salarial, de 2004 a 2007, el salario promedio de los españoles se incrementó un 12, 9\%, mientras que el de la población inmigrante lo hizo tan sólo un 13\%, lo que ensanchó la brecha salarial entre ambos colectivos.

Este aspecto económico es muy importante para el bienestar de los trabajadores inmigrantes ya que su dependencia de las rentas salariales es muy elevada, presentan un bajo nivel de acumulación de recursos (bienes inmuebles), el tamaño medio de las familias es mucho mayor que el de las poblaciones autóctonas (lo que implica cargas adicionales para los sustentadores) y dependen de dichos salarios para el envío de remesas a la familia residente en el país de origen. El bienestar económico fruto de su trabajo no 
repercute solo en la persona que lo desempeña, la presión por mantenerlo se debe también a la responsabilidad sobre esas terceras personas (con las que convive y las que quedaron en su país de origen).

Existe una incidencia diferencial de la crisis económica actual sobre los trabajadores inmigrantes. Ésta ha afectado en primera instancia a los hombres, principalmente debido a la fuerte destrucción de empleo en el sector de la construcción. Sin embargo, a medida que la caída de la actividad se ha ido extendiendo al sector servicios, el paro también ha aumentado de manera acusada entre las mujeres. No obstante la tasa de desempleo en ellas es más baja que la tasa de paro de los hombres debido a su presencia mayoritaria en sectores asociados a servicios de cuidado (personales), y servicio doméstico. Sin embargo hay que destacar que el nivel de protección legal y social de estos sectores laborales es escaso, y en general con peores condiciones laborales.

Los efectos de la pobreza y el riesgo de exclusión social son potencialmente mayores en el caso de los inmigrantes debido a diversos factores ${ }^{8}$ :

1. La situación económica previa de las familias inmigrantes es peor, con menores niveles de rentas, mayores niveles de endeudamiento y mayores cargas familiares.

2. Las personas desempleadas inmigrantes suelen ser las sustentadoras principales de los hogares, aportando la principal fuente de ingresos.

3. Debido a la menor antigüedad en el empleo y las fórmulas de contratación más precarias (incluyendo aquí el empleo irregular), la cuantía de las posibles indemnizaciones por despido a las que tienen derecho son menores o inexistentes, a la vez que al acceso de las rentas de sustitución (prestaciones y subsidios por desempleo).

4. La prolongación en el tiempo de la situación de desempleo ha generado un fenómeno de irregularidad sobrevenida, lo que conlleva que un número creciente de trabajadores inmigrantes no puedan renovar los permisos de trabajo, favoreciendo así la llamada economía sumergida.

Respecto a los posibles riesgos laborales para la salud en el lugar de trabajo, éstos serán los mismos para población autóctona y extranjera, pero si pueden existir diferencias en la percepción del riesgo y modo de enfrentarlos, debido a diferencias en la cultura preventiva de ambas sociedades. Éste es un hecho que habitualmente no se tiene en consideración y que puede estar detrás de algunos datos llamativos en siniestralidad laboral.

La revisión de la literatura apunta hacia una mayor accidentabilidad laboral en trabajadores inmigrantes ${ }^{9}$, si bien, las dificultades metodológicas para comparar los diversos estudios no dejan claro si esta relación se debe al tipo de trabajos de mayor riesgo desempeñados por este grupo poblacional (trabajo en la construcción por ejemplo), a la carga de trabajo debida a malas condiciones laborales (pluriempleo, horas extra, trabajos a destajo), a las situaciones de su situación contractual (subcontrataciones, laxitud en la adopción de medidas de seguridad e higiene laboral, etc.), a variables individuales (formas inseguras de desempeño laboral, escasa percepción del riesgo), a la ausencia de una formación e información correcta y adaptada a estos grupos de trabajadores sobre prevención de riesgos laborales, o a la acción conjunta de todas o algunas de estas posibles condiciones.

Sufrir un accidente de trabajo puede ser un acontecimiento determinante en la vida de cualquier trabajador, pero en el caso de un inmigrante puede suponer además la ruptura de todo el proceso migratorio propio y de su familia. Según datos del INSHT ${ }^{10}$, durante el 2008, la tasa de incidencia de los accidentes totales en jornada de trabajo para trabajadores de nacionalidad española fue de 4.889,3, mientras que la tasa de incidencia de los accidentes que sufren en este mismo año los trabajadores extranjeros es de 6.567,2, bastante más elevada que la de los españoles. Ocurre lo mismo en el caso de los accidentes mortales, donde la tasa de incidencia en trabajadores extranjeros fue de 7,6 frente al 4,8 de los accidentes mortales sufridos por trabajadores españoles en el mismo año. Si analizamos 
estas tasas de incidencia se observa que, tanto en población autóctona como extranjera, predomina el accidente laboral entre los varones y de forma más llamativa cuando existe contratación temporal. Sin embargo, en este último caso, cuando los contratos son temporales, se incrementa a más del doble la accidentabilidad entre el colectivo extranjero.

En relación con los accidentes in intinere, la incidencia es mayor en población nacional, pero la mortalidad de los mismos es superior entre los trabajadores foráneos.

Al igual que ocurre con los aspectos salariales, la estabilidad laboral o el tiempo de trabajo, es factible prever datos de desigualdad en aspectos relativos a condiciones de penosidad de la actividad laboral asociados a la segmentación laboral en la que se distribuye la población trabajadora inmigrante. Sin embargo, son aún escasos los estudios sobre condiciones de trabajo y riesgos laborales del mismo en población inmigrante. Algunos de ellos, procedentes principalmente de investigaciones desarrolladas desde el ámbito universitario aportan una realidad que invita a la reflexión.

Según un completo estudio de la UNED y la Fundación Sistema ${ }^{11}$ :

- Respecto a la percepción de riesgo laboral por sector de actividad son los trabajadores inmigrantes del transporte los que más perciben riesgos en su trabajo (48,6\%), seguidos de los inmigrantes empleados de la construcción (46,8\%) y de la industria (41\%), es sensiblemente menor en la agricultura $(38,3 \%)$ y se produce un gran descenso porcentual en aquellas profesiones consideradas "menos peligrosas": la hostelería $(24,3 \%)$, el comercio $(13,4 \%)$ y los servicios domésticos $(11,8 \%)$.

- Los trabajadores con más años de permanencia en España (más de 5 años) perciben más el riesgo que conlleva el trabajo que realizan; lo cual se podría interpretar como un proceso de aculturación mediante el que se asimilan valores de protección de la salud.

- Los riesgos percibidos por los trabajadores inmigrantes más frecuentes son: caídas de altura $35,9 \%$, cortes y pinchazos $31,7 \%$, golpes $31,2 \%$, caídas de objetos $22,9 \%$ y sobreesfuerzos por carga $17,4 \%$, caídas al mismo nivel $15,6 \%$, quemaduras $13,1 \%$ y desplome/derrumbamiento $12,4 \%$.

- La mayoría de la población inmigrante trabajadora estudiada señala como casos puntuales la percepción de actitudes de racismo en el lugar de trabajo (siendo algo más elevada entre la población africana). Las discriminaciones percibidas se centran más en cuestiones laborales tales como la remuneración, las tareas asignadas y el tiempo de trabajo, respecto a la población española (ver gráfica 2).

Gráfica 2. Discriminaciones laborales percibidas por población ocupada extranjera

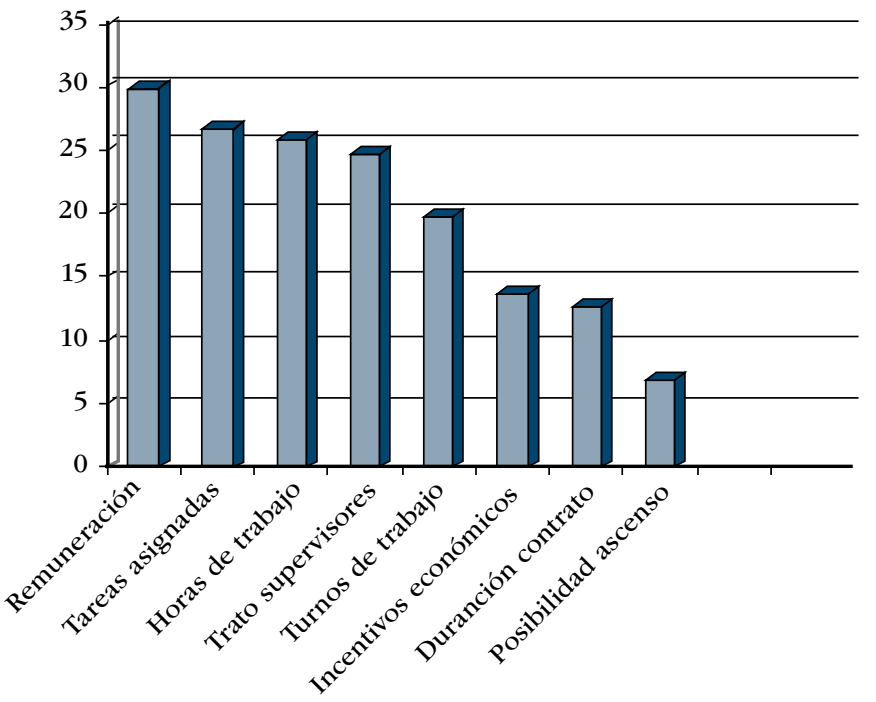

Fuente: Adaptado de GETS, Encuesta sobre las condiciones laborales de los trabajadores inmigrantes en España (2007). 
Si observamos la percepción de riesgo laboral predominante en la población inmigrante, ésta se centra prioritariamente en causas que pueden ser generadoras de accidentes de trabajo a corto plazo, omitiendo en general, riesgos con efectos a más largo plazo (los de carácter psicosocial por ejemplo). Algunos autores afirman que esta situación puede estar denotando una incompleta información y formación preventiva además de responder a la segregación de esta muestra de trabajadores por sectores de alta peligrosidad laboral ${ }^{9}$. Sin embargo, además de estas causas objetivas, también debemos considerar otros factores de carácter subjetivo y motivacional.

La experiencia vital y cultural del trabajador inmigrante, la variación en sus circunstancias personales, sus expectativas individuales, el deseo de permanecer en la sociedad de acogida y en el mercado laboral, influirán de forma más que probable en la tolerancia, estilo de afrontamiento, o incluso no consideración, de riesgos laborales interpretados como "menores" porque no supongan un claro peligro para la integridad física.

Son escasos los datos relativos a riesgos psicosociales del trabajo en inmigrantes. Una revisión europea de la literatura al respecto ${ }^{12}$ indica que, en relación con los posibles riesgos derivados de la interacción personal, la segmentación laboral de las diferentes etnias en sectores laborales determinados influye en que exista una mayor relación con trabajadores de su mismo entorno cultural, y eso disminuye posibles problemas derivados de las diferencias culturales, pero a su vez potencia la segregación y dificulta la integración y adaptación mutua de ambas sociedades. Cuando es necesario un trabajo en equipo, las diferencias interpersonales se acentúan debido a las dificultades idiomáticas, de formación y a las diversas maneras y ritmos de trabajo en el desempeño laboral. Según la revisión mencionada, esto ocurre principalmente en el sector servicios y en áreas como la sanitaria, donde (al menos en trabajos procedentes de Reino Unido) se aportan datos sobre un mayor porcentaje de conflictos interpersonales y acoso laboral en personal inmigrante.

Cuando un trabajador no comparte los códigos de interacción autóctonos puede no comprender pautas de conducta social, violar fácilmente las expectativas del grupo, rendir menos o participar de conflictos interpersonales, lo que puede favorecer respuestas agresivas hacia él, generándose hacia él posibles conductas de acoso que algunos autores consideran como un instrumento de control social ${ }^{13-14}$.

Como ocurre en general con los riesgos psicosociales, probablemente no se trate de una cuestión de causa-efecto, se trata de procesos con múltiples determinantes y factores intervinientes. En una investigación de la Universidad Autónoma de Madrid sobre acoso psicológico en población inmigrante de la Comunidad de Madrid $^{15}$, se comprobó como la desadaptación sociocultural no es un factor que determine directamente la existencia de acoso psicológico, pero sí actúa como mediador entre éste y las consecuencias para la salud del inmigrante, de forma que en situaciones de acoso laboral, a mayor desadaptación percibida por el trabajador extranjero en la sociedad de acogida, mayor sintomatología de estrés.

La satisfacción laboral y los sentimientos de estrés en relación con el trabajo en inmigrantes, ha sido objeto de estudio en algunos países. Concretamente en algunos estudios $^{16-18}$, los datos parecen indicar que la discriminación racial, particularmente en relación con el género, se muestra como una variable en clara relación con el estrés laboral. Además, asocian el estrés percibido con otros factores de riesgo tales como la sobrecarga laboral, la fatiga, malos tratos en la interacción con supervisores y/o compañeros de trabajo. En un estudio sueco ${ }^{19}$, indican que los ratios de desgaste profesional (burnout) entre inmigrantes son casi el doble que los de población sueca ( $9,9 \%$ y $5,2 \%$ respectivamente), factor que relacionan con las diferencias en las condiciones de trabajo y elevadas demandas laborales.

Los resultados de algunos trabajos en población inmigrante en España son diferentes. Por ejemplo, algunas investigaciones obtienen que no existe diferencias en riesgo laboral entre población autóctona e inmigrante que trabaja en similares circunstancias, si bien los inmigrantes padecerían exposiciones más frecuentes e intensas por el acceso mayoritario 
a puestos menos cualificados y por la necesidad de prolongar las jornadas de trabajo ${ }^{20}$. Otros trabajos incluso indican buenos niveles de satisfacción laboral en la población inmigrante y mayor satisfacción con el trato recibido por parte de los supervisores en los trabajadores extranjeros frente a los nativos ${ }^{21}$.

\section{PROBLEMAS DE SALUD MENTAL ASOCIADOS A LA INMIGRACIÓN}

No es solo el área laboral la que genera riesgos para la salud de los inmigrantes. Existe evidencia científica sobre la predisposición a padecer diversos trastornos mentales fruto de la complejidad de la experiencia migratoria en su conjunto. Esto se da en parte por la pérdida de la red social de apoyo, el distanciamiento personal que supone otra lengua y otra cultura y los cambios que se producen en la identidad individual y colectiva de estas personas.

En la persona, la identidad, tanto colectiva como individual, supone un conjunto de símbolos y valores que permiten afrontar la vida cotidiana y que descodifica y da sentido a las situaciones de la misma. Es algo que se construye y se modifica siempre en el encuentro con "el otro" que nos rodea, en un proceso de ida y vuelta que afecta a ambas partes ${ }^{22}$. Se trata de procesos dinámicos, que están en continua evolución a lo largo de nuestra historia de vida y del contexto cultural y situacional en el que nos movemos. La función de adaptación de un trabajador a un entorno social y laboral de otro país, supone la modificación de aspectos de esa identidad con vistas a una integración al medio pero sin perder la sensación de seguir siendo ellos mismos (buscando una continuidad). Sin embargo, una adecuada integración no se consigue solo de forma unidireccional. Se define como adaptación y/o integración vincular la relación de integración y aceptación mutua inmigrante-comunidad receptora ${ }^{23}$.

Los procesos de interacción más o menos traumáticos que se producen en los individuos cuando realizan un cambio de su cultura a otra diferente se ha denominado estrés aculturativo, e incluyen una amplia gama de sentimientos, emociones y conductas, tanto individuales como colectivas que padecen las personas cuando se tienen que despojar de sus referentes culturales.

Es un clásico el modelo teórico de Berry ${ }^{24}$ en el que se distinguen cuatro modalidades de aculturación, o actitudes del inmigrante para adaptarse a la sociedad de acogida sin perder su identidad personal y cultural:

- Asimilación: se produce cuando las personas deciden asumir la cultura de la sociedad de acogida, identificándose totalmente con ella y renunciando a su cultura tradicional bajo el supuesto de que así la nueva sociedad lo admitirá como un miembro más.

- Separación: la persona se involucra exclusivamente en los valores y normas culturales propias y mantiene poca o ninguna interacción con los miembros y la cultura de la sociedad que los recibe.

- Integración: implica una fuerte identificación e implicación a partes iguales, tanto en la cultura autóctona de la sociedad receptora, como con la cultura de su país de origen.

- Marginación: esta situación se deviene del rechazo tanto a la cultura de origen, como a la sociedad de destino, en estos casos la patología psiquiátrica prevalece más que en las otras situaciones, pues se rechazan ambas culturas.

Se plantea que, de ellas, la integración es quizás la forma de relación más adaptativa y probablemente la forma de relación que menos trastornos psiquiátricos conlleve, pero no habrá integración exitosa sin una nueva concepción de la cultura que implique al conjunto de conductas adaptativas que provienen de ser miembro simultáneo de diversos contextos, participando e identificándose con ambos. 
Este proceso de aculturación está vinculado a la adaptación de las personas inmigrantes y de las sociedades, que a su vez estará condicionado por los siguientes factores:

- La semejanza o diferencia cultural del país de origen con el de destino. Las sociedades semejantes minimizan el choque cultural.

- La receptividad de la cultura mayoritaria o de la sociedad de destino.

- La edad de las personas inmigrantes.

- El tipo de personalidad: que corresponde a la capacidad de adaptación al cambio y la estabilidad personal.

Las relaciones interculturales pueden producir un choque en la coexistencia de diversos valores, creencias, normas y pautas de comportamiento de las personas de diferentes culturas. Dicho choque cultural ocasiona en muchas ocasiones sentimientos de impotencia, debido en gran parte a la incapacidad de actuar competente en la nueva cultura, a la confusión sobre los roles propios y nuevos, a la identidad étnico cultural propia, y a las expectativas de conducta ${ }^{25}$.

En una reciente investigación sobre estrés aculturativo y salud en población inmigrante ${ }^{26}$ se observa cómo el estrés aculturativo es un claro determinante de procesos de discriminación en la sociedad de acogida. Además, se han obtenido correlaciones muy significativas entre estrés aculturativo y salud mental (evaluada mediante Cuestionario Goldberg), si bien, en los análisis de regresión, dicho estrés no se vale por si solo para definir la salud mental del trabajador. Estos datos corroboran la afirmación de Sam ${ }^{27}$ cuando afirma que la relación entre inmigración y salud no es lineal y sencilla, sino que se verá influenciada por factores personales (edad, predisposición genética, etc.), por factores de la sociedad de origen y de la sociedad de acogida, por el propio proceso de inmigración y por la interacción entre todos ellos.

Para algunos autores ${ }^{28}$, es clara la influencia que la cultura ejerce sobre los procesos cognitivos, afectivos, comunicativos, psicofisiológicos y conductuales, por este motivo señalan como esencial comprender el rol que la cultura tiene en la actividad interpersonal de la persona, es decir, todo aquello que tiene que ver con los patrones de enfermedad y de respuesta al estrés, cómo los factores biológicos son activados por factores culturales, y cómo esto ocurre tanto para el bienestar y la salud y como para el desarrollo de la enfermedad mental. Considerar por tanto los aspectos culturales será algo esencial para afrontar la etiopatogénesis, diagnóstico y tratamiento de las enfermedades mentales en trabajadores inmigrantes.

Los principales dificultades detectadas en la salud de los inmigrantes, según Chamizo $^{29}$, son las dificultades de acceso al sistema sanitario (mediadas por las diferencias culturales y lingüísticas) y la enfermedad más grave es el desarraigo, que se convierte en el principal determinante de la salud de dicha población. Enfrentarse a un cambio como es emigrar a otro país, es un proceso complejo y amplio, que posee unos niveles de estrés tan intensos, que en muchas ocasiones llegan a superar la capacidad de adaptación de las personas.

Estos cambios son muy diversos, aspectos tan básicos como son la alimentación, las relaciones familiares, el estatus, la lengua, la cultura, etc., por lo que en torno a la persona inmigrante, nada será como antes.

El duelo migratorio se entiende como el proceso de reorganización de la personalidad que tiene lugar cuando se pierde algo que es significativo para el sujeto, concretamente en el caso de la inmigración, tiene que ver con la reelaboración de los vínculos que la persona ha establecido con su país de origen: al salir de allí debe mantener dichos vínculos porque forman parte de su identidad, a la vez que tiene que poner en marcha una serie de nuevos vínculos que le servirán para adaptarse a la sociedad de acogida ${ }^{30}$. Se trata por tanto de un elemento esencial para el equilibrio psíquico de estas personas. 
Atxotegui ${ }^{30}$ considera que el conjunto de duelos de la inmigración se pueden agrupar en siete duelos específicos:

1. Duelo por la familia y amigos: La separación de los seres queridos, así como de las relaciones significativas, conllevan repercusiones psicológicas. Es uno de los mayores duelos a los que la persona que emigra debe de enfrentarse, ya que lo hará no solamente a nivel individual, sino también a nivel familiar (separación de hijos pequeños o de hermanos, repercusiones en la familia extensa, con los abuelos que cuidan en los países de origen etc..), sin dejar a un lado también, el proceso de reagrupación familiar, con todo lo que ello conlleva no sólo a nivel legal sino afectivo (sentimientos de culpa, soledad y abandono por ambas partes). No obstante, el proceso migratorio puede ofrecer también una oportunidad de reestructurar, a través de un período de separación, algunas relaciones conflictivas con personas significativas del país de origen.

2. Duelo por la lengua materna: La lengua materna, junto con otros aspectos más como es la cultura (con los valores y creencias que ésta conlleva en las familias), es un aspecto crucial en la vida de una persona que se ha ido elaborando a través de la historia de vida del sujeto. Por otra parte, la adquisición de una nueva lengua conlleva un enorme esfuerzo personal, así como de habilidades lingüísticas, que no todo el mundo posee, ni la capacidad tampoco de adquirir un lenguaje no verbal adecuado al contexto.

3. Duelo por la cultura: Cuando una persona emigra deja atrás toda una serie de concepciones y actitudes sobre el mundo y de cómo debe de comportarse y relacionarse dentro y fuera de él. Estas concepciones y maneras de comportamiento pueden ser muy diferentes a las propias, con el consiguiente choque con el modelo de conducta a adoptar en cada cultura. Un nuevo contexto social implica cambios en aspectos como son la alimentación, la ropa, el sentido del tiempo etc., que no siempre pueden ser vistos, por la persona que emigra, como el más saludable (por ejemplo en las comidas), respetuoso o adecuado.

4. Duelo por la tierra, los paisajes: En muchos casos, los inmigrantes estén apegados afectivamente a la tierra en la que han crecido, con sus temperaturas, climas, paisajes etc. Por otro lado, las fantasías sobre la tierra también pueden vivirse de forma intensa entre los autóctonos, en relación a temores, tales como que la emigración suponga que su país "sea invadido "por otras personas.

5. Duelo por la pérdida del estatus social: Aunque la inmigración suele conllevar una mejoría y progreso social, también suelen retroceder, a nivel de estatus, respecto al de su sociedad de origen. En ocasiones el inmigrante puede llegar con proyecto migratorio muy desajustado e idealizado, respecto a la realidad que encontrará en el país receptor, el fracaso del este proyecto personal es uno de los motivos de frustración y depresión reactiva dentro de este colectivo.

6. La pérdida de contacto con el grupo étnico de origen: Dentro de este duelo se incluyen aspectos tan complejos, como son aquellos elementos que conforman la identidad humana, como la identidad de género, la identidad generacional, la identidad religiosa, la identidad laboral, la identidad de clase social etc. Así, todos estos aspectos hacen relación al sentimiento de pertenencia a un grupo, de personas que poseen unas características similares de historia, cultura, lengua etc., que sirve a su vez como cohesión grupal para ellas.

7. La pérdida de la seguridad física: Estos riesgos no sólo son los derivados de enfermedades o lesiones físicas, sino también los derivados por los procesos de duelo, por todo aquello que la persona siente que ha perdido.

Un aspecto importante es que, a menor consistencia y elaboración del proyecto migratorio, más difícil será la elaboración del duelo. Por tanto, aquellas personas que no hayan elegido realizar un proyecto migratorio, sino que se hayan visto obligadas a huir a otro país, bien sea por problemas políticos, económicos etc., el único proyecto estará en torno al "regreso" a su lugar de origen. 
Además, el duelo migratorio es transgeneracional, debido a la identificación que hacen los hijos de inmigrantes con las figuras parentales y al contacto e interiorización a través de ellos principalmente con su cultura de origen. La complejidad del duelo de la "segundas generaciones" supone que algunos estudios hablen de mayor patología depresivo-ansiosa en los descendientes de inmigrantes de "primera generación".

Además de los posibles duelos migratorios, otro concepto esencial en la bibliografía relativa a la salud mental en inmigrantes es el denominado Síndrome del Inmigrante con Estrés Crónico y Múltiple, comúnmente conocido como Síndrome de Ulises ${ }^{31}$.

Se define como un conjunto de alteraciones psiquiátricas, que sufren algunos extranjeros por las situaciones vividas relacionadas con el hecho de ser inmigrante. En términos generales, el proceso migratorio posee unos niveles de estrés tan intensos, que en muchos casos superara la capacidad de adaptación de las personas, apareciendo en este momento los síntomas psicopatológicos.

Se caracteriza por una combinación de estresores tales como soledad, fracaso en el logro de objetivos, vivencia de carencias extremas y terror. El efecto de dichas variables se magnifica por sus características:

- Se trata de estresores múltiples y de carácter crónico que se potencian entre si y tienen carácter acumulativo.

- Se produce un importante efecto de indefensión aprendida ante los mismos

- Son de gran intensidad y relevancia para la persona

- Se suelen asociar con un importante déficit de la red de apoyo social

- Los propios síntomas se convierten en un obstáculo para el proyecto migratorio

La sintomatología clínica asociada se expone de forma abreviada en la Tabla 1. Se trata de una sintomatología variada con diversas expresiones psicopatológicas:

Tabla 1. Expresión clínica del Síndrome del Inmigrante con Estrés Crónico y Múltiple.

\begin{tabular}{|c|c|}
\hline Sintomatología Depresiva & $\begin{array}{l}\text { Tristeza, sentimientos de fracaso, indefensión aprendida, } \\
\text { llanto, sentimientos de culpa. }\end{array}$ \\
\hline Sintomatología Ansiosa & $\begin{array}{l}\text { Irritabilidad, alteraciones del sueño, tensión, nerviosismo, } \\
\text { ideas y preocupaciones recurrentes. }\end{array}$ \\
\hline Sintomatología Somática & Cefaleas, fatiga crónica, dorsalgias. \\
\hline Aspectos Confusionales & $\begin{array}{l}\text { Fallos de memoria, de atención, baja capacidad de } \\
\text { concentración, sentimientos de estar perdido, desconfianza. }\end{array}$ \\
\hline Aspectos Culturales & $\begin{array}{l}\text { Interpretación de la sintomatología desde aspectos relativos } \\
\text { a la cultura tradicional de origen. }\end{array}$ \\
\hline
\end{tabular}

El afrontamiento de esta sintomatología en personas inmigrantes exige por parte de los profesionales sanitarios un abordaje trascultural ${ }^{32}$ :

1. Respecto al idioma: Será imprescindible indagar en la lengua de origen y conocimiento de nuestro idioma, adaptando la evaluación clínica a dichas circunstancias.

2. Manteniendo una concepción étnica de la enfermedad: Tanto en su etiología como en su expresión sintomática.

El área global de los sentimientos y conductas depresivas posee aspectos comunes entre todas las culturas (tristeza, anhedonia, tensión física, apatía, dificultad de concentración y atención, pérdida de interés e ideas de insuficiencia e incapacidad), sin embargo, existen marcadas diferencias entre los grupos étnicos vinculadas a las diferentes dinámicas culturales, respecto a los sentimientos de culpa, ideas de suicidio y expresión (verbal y conductual de la sintomatología percibida).

Otras patologías psiquiátricas como la psicosis también ha sido objeto de estudio desde esta perspectiva cultural, indicando algunos trabajos una mayor incidencia en 
población inmigrante. Parece que este hecho se relaciona con una mayor vulnerabilidad por circunstancias propias del proceso migratorio como la desigualdad social (desempleo, hacinamiento, fragmentación familiar) y la vivencia de actitudes racistas y discriminatorias, actuando de forma sinérgica con variables individuales, la historia familiar, el aislamiento social $^{33}$.

\section{RELACIÓN ENTRE SALUD MENTAL Y SALUD LABORAL}

Como hemos visto a lo largo de la revisión de la literatura expuesta en este trabajo, hasta el momento, la mayor parte de las publicaciones que abordan estos temas se han centrado en el análisis estadístico, principalmente descriptivo y sociodemográfico, de la población trabajadora inmigrante en el ámbito laboral o en la descripción y estudio de la prevalencia de sus principales patologías o problemas de carácter psiquiátrico. Son aún escasos los estudios de investigación que aborden ambos temas de forma integrada y más aún que se centren en líneas de actuación en integración sociolaboral, salud mental y salud laboral de los trabajadores inmigrantes en las organizaciones.

Son diversos los estudios ${ }^{34-36}$ que centrándose en un aspecto concreto del trabajo precario desempeñado por población inmigrante (como la temporalidad en el empleo) relacionan estas condiciones con elevados costes psíquicos y sociales, mayor deterioro de la salud psicológica, desmotivación e insatisfacción laboral.

Concretamente, parece que la inestabilidad laboral y el trabajo "informal" genera una incertidumbre vital que se relaciona con mayores niveles de ansiedad, pesimismo sobre el futuro, mayor sintomatología de estrés e incremento de trastornos mentales "menores" ${ }^{37}$, así como un incremento de las manifestaciones psicosomáticas, fatiga, exacerbación de rasgos indicativos de trastornos de personalidad y violencia ${ }^{38}$.

Brunner $^{39}$ señala que la baja autoestima, el aislamiento social y la falta de control sobre el trabajo influyen de manera negativa sobre la salud mental y la respuesta al estrés activada de forma frecuente y prolongada puede llevar consigo problemas de salud como depresión, mayor vulnerabilidad a procesos infecciosos, diabetes, hipertensión, hipercolesterolemia y por tanto, aumento del riesgo de cardiopatía isquémica y para la patología vascular cerebral. Los procesos sociales y laborales interactúan por tanto con la salud física y mental.

Quizás la variable más conocida por su capacidad de moderación entre los aspectos laborales y la salud mental es el apoyo social.

Existe abundante literatura sobre la capacidad amortiguadora del apoyo social frente a la depresión en población inmigrante y cómo este apoyo evoluciona de manera paralela al estatus del inmigrante y sus diferentes fases de asentamiento en la población de acogida, independientemente del origen étnico ${ }^{40-41}$.

El entorno laboral es el principal motor de estatus social, estabilidad e integración entre la población extranjera, de ahí la importancia del apoyo social percibido en el lugar de trabajo como factor clave para el equilibrio emocional.

Según Juan Díez Nicolás ${ }^{42}$,"la importancia que tiene la inserción laboral para los inmigrantes es tal que algunos autores establecen una relación directa entre ésta y su integración social", desde esta perspectiva, establecer estrategias de evaluación de los riesgos y prevención que tengan en cuenta sus características específicas (el idioma por ejemplo) será clave para su salud física, psicológica, social y laboral. La tipología de riesgo con el perfil socio-laboral que se le relaciona permitirá identificar mejor las necesidades de intervención preventiva. 


\section{BUENAS PRÁCTICAS EN SALUD LABORAL DE LOS TRABAJADORES INMIGRANTES}

El Plan Estratégico de Ciudadanía e Integración del Ministerio de Trabajo ${ }^{43}$ propone en el área del empleo:

- Adecuar la normativa sobre el empleo y Seguridad Social, a fin de garantizar la igualdad de derechos y deberes.

- Mejorar de modo continuado la gestión de los flujos migratorios.

- Promover el mantenimiento del empleo, la promoción profesional y la formación, así como la adecuación de las competencias de la población trabajadora inmigrante a las oportunidades del mercado de trabajo.

- Mejorar los dispositivos de intermediación en el mercado laboral.

- Luchar contra la contratación irregular de trabajadores inmigrantes en la economía sumergida.

- Luchar contra la discriminación y por la igualdad de oportunidades de las personas inmigrantes en el mercado de trabajo y en las empresas.

- Fomentar la gestión de la diversidad en las empresas.

La movilidad geográfica es una característica esencial del mundo de hoy. Los avances tecnológicos y de comunicación facilitan la globalización laboral y con ello el movimiento de la población trabajadora. El pluralismo cultural forma ya parte de nuestro entorno laboral y está llamado a ser aún mayor, pero a su vez, en las organizaciones confluyen los mismos prejuicios y estereotipos presentes en la sociedad. Atender a esta realidad es una obligación tanto para las sociedades de acogida como para las empresas que la conforman.

Por otro lado, como señalan Porthé et al. ${ }^{44}$, "aunque la motivación económica sea el sustrato sobre el que se asienta el proceso migratorio, no se puede tomar el colectivo de inmigrantes como un contingente de trabajadores homogéneo". Su origen diferente hace que provengan de experiencias laborales plurales, con diferentes disciplinas de trabajo, y esto es algo a considerar tanto en su proceso formativo como en la prevención de riesgos laborales que les afecten.

Desde esta perspectiva, la consideración de la población inmigrante en relación a la salud laboral deberá contemplar algunos aspectos que consideramos de especial relevancia y que proponemos en el siguiente decálogo:

1. Cumplimiento estricto de la legislación vigente en los procesos de selección, contratación y desarrollo de la carrera profesional.

2. Desarrollo de una cultura empresarial que favorezca la diversidad, la comunicación intercultural y la prevención de conflictos, con políticas explícitas de no exclusión y medidas de no discriminación personal ni profesional por motivos relacionados con la religión, raza o nacionalidad (mediante Códigos de Conducta Organizacionales), así como de integración multicultural e igualdad de oportunidades en todos los niveles de la empresa.

3. Colaboración con los agentes sociales del entorno y proyectos comunitarios para el desarrollo de la función social en la gestión de los flujos migratorios.

4. Inclusión de aspectos necesarios para una correcta integración en la organización laboral dentro de los programas de acogida de los nuevos trabajadores.

5. Información y formación específica en aspectos técnico-profesionales necesarios para el desempeño del trabajo y pautas de actuación preventiva frente a los posibles riesgos psicosociales: competencias profesionales.

6. Información y formación específica en aspectos culturales y de interacción personal (idiomas, trabajo en equipo, habilidades sociales, resolución de conflictos...) cuando sean necesarios para la adecuada integración de todo el colectivo organizacional (inmigrantes y nativos): competencias psicosociales. 
7. Consideración de los aspectos culturales en los procesos de vigilancia de la salud:

a. Idioma: Con la elaboración de Historias Clínico-Laborales bilingües si es necesario $^{45}$.

b. Consideración de la concepción étnica de la enfermedad. Tanto a nivel etiológico como en la forma de expresión clínica individual y colectiva.

c. Manejo de psicofármacos atendiendo a las indicaciones especiales (en dosificación y elección del fármaco por su eficacia, seguridad y tolerabilidad) para determinados grupos étnicos.

8. Inclusión de los aspectos culturales en los procesos de evaluación de riesgos:

a. Diferencias en la percepción del riesgo

b. Estilos no funcionales de afrontamiento de los riesgos laborales

9. Desarrollo de líneas de investigación sobre procesos de inclusión de los trabajadores inmigrantes y efectos de la diversidad cultural en las empresas.

10. Implicación de todos los estamentos de la organización en las actuaciones y políticas de integración, que no solo deben ir dirigidas a la población trabajadora inmigrante sino al conjunto de la empresa ya que la integración implica a ambas partes (adaptación o integración vincular).

El cuidado y respeto por el medio ambiente, la seguridad y salud en el trabajo y la calidad en los procesos productivos, son tres ámbitos que las organizaciones públicas y privadas de nuestro entorno comienzan a recoger en sus modelos empresariales y políticas de Responsabilidad Social Corporativa. En función de la realidad laboral de la población inmigrante presentada en este artículo y de cómo ésta se relaciona con la salud mental y laboral de estos profesionales, la gestión de la diversidad cultural de los recursos humanos se propone como un reto que nuestras organizaciones tendrán que abordar e incluir en dichas políticas de responsabilidad social. Para ello, será esencial un mayor conocimiento científico del tema así como la implicación y el apoyo de las Administraciones Públicas.

\section{REFERENCIAS BIBLIOGRÁFICAS}

1. Asamblea General de las Naciones Unidas. Declaración Universal de los Derechos Humanos. Resolución 217 A (III). París: Organización de las Naciones Unidas (ONU); 1948.

2. Instituto Nacional de Estadística. Disponible en: www.ine.es

3. Barrón A, Sánchez E. Estructura Social, apoyo social y salud mental. Psicothema 2001; 13 (1): 17-23.

4. Ley Orgánica 2/2009, de 11 de diciembre, de reforma de la Ley Orgánica 4/2000, de 11 de enero, sobre derechos y libertades de los extranjeros en España y su integración social. BOE $n^{\circ} 299$ del 12 de diciembre de 2009.

5. Real Decreto 557/2011, de 20 de abril, por el que se aprueba el Reglamento de la Ley Orgánica 4/2000, sobre derechos y libertades de los extranjeros en España y su integración social, tras su reforma por Ley Orgánica 2/2009. BOE n 103 del 30 de abril de 2011.

6. Pajares M. Inmigración y Mercado de Trabajo. Informe 2010. Observatorio Permanente de la Inmigración. Madrid: Ministerio de Trabajo e Inmigración; 2010.

7. Castillo JJ, Prieto C. Condiciones de Trabajo. Un enfoque renovador de la sociología del trabajo. Madrid: CIS; 1990.

8. Vizán C. Los inmigrantes ante la crisis económica: ¿De la precariedad a la exclusión? Los efectos de la crisis. Rev. Mugak. Centro de Estudios y Documentación sobre Inmigración, Racismo y Xenofobia 2011; 54.

9. Tezanos JF, Díaz V. Condiciones Laborales de los Trabajadores Inmigrantes en España. Madrid: Fundación Sistema; 2008.

10. INSHT. Condiciones laborales y siniestralidad en el colectivo de trabajadores inmigrantes 2008. Disponible en: http://www.insht.es/Observatorio/Contenidos/InformesPropios/Desarrollados/Ficheros/Informe\%20 siniestralidad\%20inmigrantes.pdf 
11. Grupo de Estudio sobre Tendencias Sociales (UNED), Fundación Sistema. Encuesta sobre condiciones laborales de los trabajadores inmigrantes en España. Ministerio de Trabajo y Asuntos Sociales 2007. Disponible en: www.seg-social.es/prdi00/groups/public/documents/.../100598.pdf

12. European Agency for Safety and Health at Work. Literature Study of Migrant Workers. 2008. Disponible en: http://osha.europa.eu/en/publications/literature_reviews/migrant_workers

13. Nelson RB, Tedeschi JT. Aggression and violence: Social interactionists' perspectives. Wshington DC: American Psychological Association; 1993.

14. Hoel H, Cooper CL. Organizacional effects of buying. En S Einarsen, H Hoel, D Zapf y CL Cooper (Eds.), Bullying and Emocional Abuse in the Workplace: International Perspectives in Research and Practice. London: Taylor \& Francis Books Ltd; 2003.

15. Moreno Y. Acoso psicológico en la población inmigrante de la Comunidad de Madrid: los efectos de la desadaptación social y de las variables personales. Tesis Doctoral no publicada. Facultad de Psicología 2010. Universidad Autónoma de Madrid.

16. Ruhs M. Managing the Immigration and Employment of non-EU Nationals in Ireland. Studies in Public Policy 2005; 19.

17. Smith A, Wadsworth E, Shaw Ch, Stansfeld S, Bhui K, Dhillon K. Ethnicity, work characteristics, stress and health. Health \& Safety Excecutive Research Report 2005; 308

18. McKay S, Craw M, Chopra D. Migrant workers in England and Wales: An assessment of migrant worker health and safety risks. Working Lives Research Institute. London: Metropolitan University; 2006.

19. Hallsten L, Bellaagh K, Gustafsson K. Utbränning i Sverige - en populations studie [Burnout in Sweden - a study among the workforce]. Arbetslivsinstitutet, Arbete och hälsa. Vetenskaplig skriftserie $2002 ; 6$.

20. García AM, López MJ, Agudelo AA, Ruíz C, Ahonen EQ, Porthé V. Condiciones de trabajo y salud en inmigrantes. Proyecto ITSAL: entrevistas a informantes clave. Gac Sanit 2009; 23(2): 91-97.

21. Zabaleta E. Inserción y dinámicas laborales de los trabajadores inmigrantes. Imserso; 2004.

22. Centro de Investigación para la Paz. Dossier para una educación intercultural. Madrid: CIP-FUHEM; 2005. Disponible en: http://www.fuhem.es/cip-ecosocial/dossier-intercultural/contenido/home.htm

23. Sayed-Ahmad N. Grupo de Trabajo Salud Mental Transcultural. Inmigración y Salud mental. Cuadernos Técnicos 2. Córdoba: Asociación Andaluza de Neuropsiquiatría; 2006.

24. Berry J.W. Managing the process of acculturation for problem prevention, in Mental Health Services for refugees.1991. Washington.DC. National Institute of Mental Health; 1991.

25. Basabe N., Páez D., Zlobina A. Adaptación de los inmigrantes extranjeros en España: superando el choque cultural en Migraciones $n^{\circ}$ 15. 2004. Madrid. Instituto Universitario de Estudios sobre Migraciones de la Universidad Pontificia Comillas; 2004.

26. Hernández F. Influencia del estrés aculturativo en la salud general de los inmigrantes. Estudio en tres grupos culturales de la Comunidad de Madrid. Tesis Doctoral no publicada. Facultad de Psicología 2011. Universidad Autónoma de Madrid.

27. Sam D. Acculturation and health. Handbook of acculturation. London: Cambridge University Press; 2006

28. Alarcón R. Pasado, presente y futuro de la Psiquiatría Cultural. 2000. Madrid. Monografías de Psiquiatría; 2000

29. Chamizo J. El derecho a la protección de la salud de los inmigrantes, conferencia inaugural de la I Jornada de Coordinación de Atención Sanitaria a inmigrantes en Andalucía. 2002. Sevilla. Fundación Progreso y Salud; 2002.

30. Sánchez G, López MJ. Ansiedad y modos de aculturación en la población inmigrante. Apuntes de Psicología 2008; 26 (3): 399-410.

31. Atxotegui J. Los duelos de la migración: una aproximación psicopatológica y psicosocial. En: E Perdiguero y JM Comelles. Medicina y Cultura. Estudios entre la Antropología y la Medicina. Barcelona: Bellatera; 2000.

32. Martínez M, Martínez A. Patología psiquiátrica en el inmigrante. Anales 2006; 29 (1).

33. Hutchinson G, Haasen C. Migration and schizophrenia: The changes for European psychiatry and implications for the future. Soc Psychiatry Psychiatr Epidemiol 2004; 39:350-357.

34. Bohle P, Quinlan M, Kennedy D, Williamson A. Working hours, work-life conflicto and health in precarius and "permanent" employment. Rev Saudade Publ. 2004; 38:19-25.

35. Burchell B. The effects of labour market position, job insecurity and unemployment on psychological health. Social change and the experience of unemployment. Oxford: Oxford University Press; 1994. 
36. Bardasi E, Francesconi M. The impact of atypical employment on individual wellbeing: evidence from a panel of British workers. Soc Sci Med. 2004; 58:1671-88.

37. Ludemir AB, Lewis G. Informal work and common mental disorders. Soc Psychiatry Psychiatr Epidemiol. 2003; 38:485-9.

38. Delclós J, Betancourt O, Marqués F, Tovalín H. Globalización y Salud Laboral. Arch Prev Riesgos Labor 2003; 6 (1): 4-9.

39. Brunner E. Social Organization, Stress and Health. En: M Marmot y R Wilkinson (eds.), Social Determinants of Health, New York: Oxford University Press; 1999.

40. Martínez MF, García M, Maya I. El efecto amortiguador del apoyo social sobre la depresión en un colectivo de inmigrantes. Psicothema 2001; 13 (4): 605-610.

41. García M, Martínez MF, Albar MJ. La elección de fuentes de apoyo social entre inmigrantes. Psicothema 2002; 14 (2): 369-374.

42. Díez, J. Las dos caras de la inmigración. MTAS 2005. p.244.

43. Secretaría de Estado de Inmigración y Emigración. Dirección General de Integración de los Inmigrantes. Madrid: Ministerio de Trabajo e Inmigración; 2007. Disponible en: http://www.tt.mtas.es/periodico/ inmigracion/200702/plan.pdf.

44. Porthé V, Amable M, Benach J. La precariedad laboral y la salud de los inmigrantes en España: ¿qué sabemos y qué deberíamos hacer?. Arch Prev Riesgos Labor 2007; 10 (1): 34-39.

45. Otero C, Novillo M.L., Pareja S, Flis M, Yubero L, Gómez JM. Modelo de Historia Clínico-Laboral Bilingüe para trabajadores inmigrantes. Medicina del Trabajo 2006; 15 (2): 40-55.

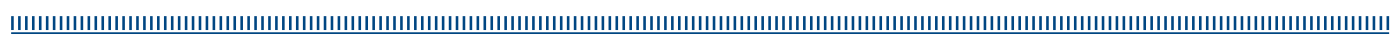

